FU + intermediate-dose folinic acid in the treatment of advanced colorectal cancer. Ann Oncol 1992, 3, 87-88.

25. Hryniuk WM. The importance of dose-intensity in the outcome of chemotherapy. In De Vita VT, Hellmans S, Rosemberg SA, eds. Important Advances in Oncology. Philadelphia, J.B. Lippincott, 1988, 121-141.

26. Poon MA, O'Connell MJ, Moertel CG, et al. Biochemical modulation of fluorouracil: evidence of significant improvement of survival and quality of life in patients with advanced colorectal carcinoma. F Clin Oncol 1989, 7, 1407-1418.

27. Nobile $M$, Canobbio L, Sobrero A. A randomized trial of 5fluorouracil and high dose leucovorin in untreated advanced colorectal cancer patients. In Rustum Y, McGuire J, eds. The Expanding Role of Folates and Fluoropyrimidines in Cancer Chemotherapy. Exp Med Biol 1988, 244, 213-218.

28. Nordic Gastrointestinal Tumor Adjuvant Therapy Group. Superiority of sequential methotrexate, fluorouracil and leucovorin to fluorouracil alone in advanced symptomatic colorectal carcinoma: a randomized trial. $\mathcal{f}$ Clin Oncol 1989, 7, 1437-1446.

29. Herrmann R. Biochemical modulation of 5-fluorouracil. Cancer Treat Rev 1990, 17, 51-55.
30. Valone FM, Friedman MA, Wittlinger PS. Treatment of patients with advanced colorectal carcinomas with fluorouracil alone, high dose leucovorin plus fluorouracil or sequential methotrexate, fluorouracil and leucovorin. A randomized trial of the Northern California Oncology Group. $f$ Clin Oncol 1989, 7, 1427-1436.

31. Di Costanzo F, Bartolucci R, Calabresi F, et al. Fluorouracil alone versus high dose folinic acid and fluorouracil in advanced colorectal cancer: a randomized trial of Italian Oncology Group for Clinical Research (GOIRC). Ann Oncol 1992, 3, 371-376.

32. Calabresi F, Repetto $M$. Doxifluridine in advanced colorectal cancer. F Surg Oncol 1991, 2, 124-128.

33. Alberto P, Winkelmann JJ, Paschoud N, et al. Phase I study of oral doxifluridine using two schedules. Eur f Cancer Clin Oncol 1989, 25, 905-908.

Acknowledgements-The following investigators are co-authors of the study: F. de Braud, M. Di Bartolomeo, Milano; A. Guglielmi, Genova; L. Frassineti, P. Innocenti, Forli; P. Comella, R. Casaretti, Napoli; D. Turci Ravenna; S. Perrone, Milano; F. Berardi, Bari; M. Barduagni; Roma; A. Pandolfi, Milano.

\title{
How Cost-effective is Breast Cancer Screening in Different EC Countries?
}

\author{
B. Martin van Ineveld, Gerrit J. van Oortmarssen, Harry J. de Koning, \\ Rob Boer and Paul J. van der Maas
}

\begin{abstract}
Should the decision to start breast cancer screening in the Netherlands and in the U.K. be followed by other EC countries? This question has been addressed in an exploratory analysis of the differences in cost-effectiveness of breast cancer screening in Spain, France, the U.K. and the Netherlands. A detailed cost-effectiveness analysis of breast cancer screening in the Netherlands has been used as the starting point. Country specific data on incidence, mortality, demography, screening organisation and price levels in health care have been used to predict the costs and effects of nationwide screening programmes, in which women aged 50-70 are invited for 2-yearly mammographic screening. The relative effect of screening is highest in the U.K. (16.55 life-years gained per 1000 screens) and lowest in Spain (8.23 life-years gained per 1000 screens). The cost per screen is highest in Spain (£38) and lowest in the U.K. (£18). In comparison with the yearly health expenditures per capita, the cost per lifeyear gained is 2.8 times higher in the Netherlands, 3.1 times higher in the U.K., 6.5 times higher in France and 20.6 times higher in Spain. These marked differences show that no uniform policy recommendations for breast cancer screening can be made for all countries of the EC.
\end{abstract}

Eurf Cancer, Vol. 29A, No. 12, pp. 1663-1668, 1993.

\section{INTRODUCTION}

TRIALS FOR screening on breast cancer, conducted in north-west Europe in the past decade, have shown that early detection will result in a lower mortality from breast cancer [1-6]. Thus far, a positive effect has only been demonstrated in women over the age of 50 [7]. Cost-effectiveness studies performed in the U.K. [8] and in the Netherlands [9] indicate that the costs per life-year

Correspondence to B.M. van Ineveld.

B.M. van Ineveld is at the Institute for Medical Technology Assessment, Institute of Health Care Policy and Management; and G.J. van Oortmarssen, H.J. de Koning, R. Boer and P.J. van der Maas are at the Department of Public Health, Erasmus University Rotterdam, P.O. Box 1738, 3000 DR Rotterdam, The Netherlands.

Received 12 Feb. 1993; accepted 29 Mar. 1993. gained are relatively low in comparison to many other health care provisions. As a result of these findings, nationwide screening programmes are now being implemented in the U.K., the Netherlands, Finland and Sweden.

An interesting question is whether the conclusions about costeffectiveness of breast cancer screening may be drawn for other countries in the European Community as well. The effects of a breast screening programme depend on many factors, such as incidence and mortality rates, quality of the screening test, participation rates, and screening policy. The cost-effectiveness is further influenced by the cost of the screening programme and by extra costs or savings in the diagnosis and treatment of breast cancer. Quite large differences regarding these factors exist between countries. For example, the crude mortality rate for 
breast cancer is lowest in Spain, where it is less than half of the rate in the U.K. which has the highest rate [10].

A further question is the interpretation of cost-effectiveness ratios in different countries in view of differences in wealth (gross domestic product, GDP), health status of the population, and health care expenditures.

We have performed an exploratory analysis of the differences in cost-effectiveness ratios of breast cancer screening in four countries. In this analysis, which builds on our detailed analysis for the Netherlands, the following questions have been addressed:

- Is sufficient information on key factors available to enable exploratory cost-effectiveness calculations in other EC countries?

- How much different are the ratios in other countries in comparison to the ratio for the Netherlands?

- How do these ratios compare to the general and the health-care oriented economic indicators in the countries?

With the outcomes of this analysis we will discuss to what extent they contribute to recommendations regarding the implementation of breast cancer screening in different countries.

\section{MATERIALS AND METHODS}

Our detailed analysis of the costs and effects of breast cancer screening in the Netherlands is used as a starting point $[9,11]$. Three countries were chosen as illustration: Spain (lowest breast cancer mortality), France (intermediate mortality), and the U.K. (highest mortality). The costs per life-year gained in each country are adapted on the basis of available knowledge about the screening programme, the epidemiology, demography, and the costs of screening and the changes in the related medical costs. The life-years have not been corrected for the quality of life. Considerations about the quality of life for the Netherlands can be found in [9].

\section{The screening programme}

In order to facilitate a direct comparison of the different countries, we have first considered the hypothetical case that the Dutch screening policy and organisation would be applied to the other countries. In the Netherlands, women aged 50-70 are invited for 2-yearly mammographic screening. The attendance rate is assumed to decrease from $75 \%$ at age 50 to $65 \%$ at age 70 . Screening is organised as a specialised programme, with breast cancer screening units operating independently from other health care services managed by regional boards. The programme is supervised by a (small) national organisation which also takes care of training, quality control, and evaluation. In the U.K., screening is organised in a similar way. The Dutch estimated costs are $£ 20.30$ (NLG73) per screen in this type of organisation [9].

As an alternative, we considered an organisation of the programme, in which screening takes place as an additional service in existing diagnostic centres which are either independent or linked to private practices or hospitals. This attached organisation is likely to be more realistic in (parts of) France and Spain. Although the use of existing facilities could be costsaving, the utilisation of mammographic equipment might be low with 800-1100 screens per year [12], compared with $10000-12000$ in a specialised programme. In a specialised programme it is possible to optimise the number of newly implemented screening units. For an attached programme the number of existing diagnostic centres is given and is too excessive for an efficient programme [13]. The costs of a horizontal programme in France have been estimated to be between $£ 30.20$ and 34.50 per screen (FF348-398 [12]).

\section{Epidemiology and demography}

The simulation package MISCAN [14] has been used to simulate the impact of screening on breast cancer morbidity and mortality. The development of preclinical screen-detectable invasive breast cancer is modelled by three distinguished stages which reflect the size of the tumour and may be preceded by ductal carcinoma in situ (DCIS). Key parameters of the model are the mean duration of preclinical screen-detectable stages, the sensitivity of the screening test, and the improvement in prognosis for screen-detected cases. The model parameters used in the Dutch cost-effectiveness analysis have been estimated on the basis of data from the Dutch pilot studies in Nijmegen and Utrecht. The estimates for the improvement in prognosis for screen detected cases are based on the randomised trials in Sweden. The resulting model closely reproduces age-specific breast cancer incidence and mortality as observed in the Netherlands $[9,15]$.

This model has been adapted to reproduce the age-specific incidence and mortality rates $[16,17]$ of breast cancer in the three other countries as well. Incidence and mortality are interrelated via the clinical stage distribution and the (stagespecific) survival rate. The ratio incidence:mortality is not equal in the four countries (Table 1). Hence, we had to change their interrelation, and in the absence of precise information we decided to fix the stage-specific survival rates. Using the Dutch stage distribution, based on clinically diagnosed cancers in Nijmegen and Utrecht, resulted in a good fit of Spanish incidence and mortality data. For France, we had to assume a more favourable clinical stage distribution, whereas for the U.K. the distribution is less favourable than in the Netherlands. Details are given in the Appendix.

Absolute numbers of breast cancers and breast cancer deaths, and total costs, have been calculated on basis of the present and projected age-structure of the female population in the countries under consideration [18]. The present size of age group 50-70 years is presented in Table 1.

\section{Clinical management of breast cancer}

Assumptions about diagnostic and treatment procedures, and care of (advanced breast cancer) patients, are based on Dutch data $[20,21]$ and have not been modified for the other countries. Among these assumptions are the proportion of cases receiving

Table 1. Incidence and mortality rates of breast cancer, and size of the female population in fout $E C$ countries

\begin{tabular}{lrrrr}
\hline & Spain & France & $\begin{array}{c}\text { United } \\
\text { Kingdom }\end{array}$ & $\begin{array}{c}\text { Netherlands } \\
{[19]}\end{array}$ \\
\hline Breast cancer, crude rates & & & & \\
$\quad$ (per 105 women) & & & & \\
Incidence[16] & 51.1 & 81.0 & 85.0 & 101.3 \\
$\quad$ Mortality[17] & 24.9 & 32.9 & 52.0 & 41.7 \\
$\quad$ Incidence/mortality & 2.1 & 2.5 & 1.6 & 2.4 \\
Female population[18] & & & & \\
$\quad$ (in thousands) & & & & \\
$\quad$ Total & 19700 & 28500 & 28300 & 7500 \\
50-70 years & 4180 & 5780 & 6000 & 1490 \\
\hline
\end{tabular}


Table 2. Economic indicators for four EC countries in pounds sterling $[22,23]$

\begin{tabular}{lrrrc}
\hline & Spain & France & $\begin{array}{c}\text { United } \\
\text { Kingdom }\end{array}$ & Netherlands \\
\hline $\begin{array}{c}\text { Gross domestic product } \\
\text { (GDP) per capita (£) }\end{array}$ & 7090 & 9960 & 9540 & 9350 \\
$\begin{array}{c}\text { Health care expenditures } \\
\text { per capita (£) }\end{array}$ & 470 & 890 & 580 & 760 \\
$\begin{array}{c}\text { GDP purchasing power } \\
\text { parity relative to U.K. }\end{array}$ & 181.24 & 11.53 & 1.00 & 3.61 \\
$\begin{array}{c}\text { Correction GDP-PPP for } \\
\text { price level differences in } \\
\text { health care relative to U.K. }\end{array}$ & 1.28 & 1.09 & 1.00 & 1.09 \\
\hline
\end{tabular}

breast conserving therapy, the treatment and care of advanced disease, and the number of breast cancer related mammograms made in the absence of a screening programme.

\section{CosTs}

The costs that are taken into account are the costs of the screening programme, and the changes in the direct medical costs of diagnosis, treatment, and care of breast cancer as a result of screening. Nearly all cost estimates were originally based on Dutch data. To eliminate temporary price fluctuations between countries the currencies are converted into pounds sterling with purchasing power parties (PPP), instead of exchange rates (Table 2). However, these PPP are based on the GDP of countries. The health care system as such can be relatively more or less expensive, depending on efficiency, the income of people working in the health care system, as well as differences in medical treatment. In view of these differences, health care-specific PPP have also been published for the year 1985 [22]. We have constructed estimates of health care-specific PPP on the basis of most recent PPP [23] based on the GDP, assuming a constant relative difference between PPP for health care and for the GDP as observed in 1985. A uniform set of health care services in the U.K. is $9 \%$ cheaper than in the Netherlands, relative to the standard set of goods and services reflecting the GDP of both countries. Between France and the Netherlands there is no difference. For Spain, however, this set is $19 \%$ more expensive.

\section{Calculation of effects and costs}

A screening programme has been simulated which starts in 1990 , involves a 4-year build-up period, and is assumed to stop in 2017. This long simulation period was chosen because of the lag-time between screening efforts and the major effects. In the initial years of a screening programme, enormous costs are made but hardly no effects in terms of mortality reduction or life-years gained occur. Only after more than 20 years are these effects expected to reach a more or less steady-state situation. All effects of the screening programme that occur after 2017 are taken into account. The cost-effectiveness is calculated from the total costs and the total number of life-years gained. A $5 \%$ discount rate is applied on both costs and effects.

\section{Two sets of assumptions}

Two comparisons of the effects and costs of breast cancer screening between the four countries are presented. First, only epidemiological and demographical differences between the countries are taken into account, assuming that the screening EXC 29:12-8 programme has the same specialised organisation in all four countries, and difference in price levels in health care are neglected. As an alternative, an attached organisation of screening in Spain and France is assumed, and the costs are adapted to the respective price levels of health care in the four countries.

\section{RESULTS}

The principal objective of breast cancer screening is to reduce the risk of dying from breast cancer. Therefore, the main effect measures are the number of life-years gained and the reduction in number of breast cancer deaths, which are presented in Table 3. Differences between the countries in absolute numbers of lifeyears and deaths are of course influenced by the size of the female population. Relative figures (per 1000 screenings) show that other differences, especially in the level of breast cancer mortality, but to a lesser extent also the differences in incidence, stage distribution and the age structure of the female population, play an important role. The relative effect of screening is highest in the U.K. and lowest in Spain. The average gain in life expectancy per life saved is approximately 15 years in all countries. The mortality reduction reaches its maximum in the year 2015, when 2600 breast cancer deaths are expected to be prevented in the U.K. during that year, and 700 in the Netherlands.

When only the epidemiological and demographical differences are taken into account, and no differences in price levels or screening organisation are assumed, then the costs of the screening programme are proportional to the size of the average population of the four countries. Part (b) of Table 3 gives the resulting costs in the year 2015. Although the current female population aged 50-70 in the U.K. is larger than in France (see

Table 3. The total effects of mass screening for breast cancer between 1990 and 2017 and the costs (in 2015) in the four EC countries. No discounting

\begin{tabular}{|c|c|c|c|c|}
\hline & Spain & France & $\begin{array}{l}\text { United } \\
\text { Kingdom }\end{array}$ & Netherlands \\
\hline \multicolumn{5}{|l|}{ (a) Effects } \\
\hline \multicolumn{5}{|l|}{$\begin{array}{l}\text { Breast cancer deaths } \\
\text { prevented }\end{array}$} \\
\hline Total: 1990-2017 & 22000 & 42000 & 72000 & 17000 \\
\hline Per 1000 screens & 0.57 & 0.73 & 1.36 & 1.08 \\
\hline In 2015 & 800 & 1600 & 2600 & 700 \\
\hline \multicolumn{5}{|l|}{ Life-years gained } \\
\hline Total: $1990-2017$ & 316000 & 649000 & 1046000 & 261000 \\
\hline Per 1000 screens & 8.23 & 11.40 & 19.59 & 16.55 \\
\hline (b) Cost of screening in & \multicolumn{4}{|c|}{2015 (1990 prices) } \\
\hline \multicolumn{5}{|l|}{$\begin{array}{l}\text { (bl) Uniform screening } \\
\text { system in } 2015\end{array}$} \\
\hline Per screen $(£)$ & 20 & 20 & 20 & 20 \\
\hline Million pound sterling & 34 & 53 & 48 & 15 \\
\hline $\begin{array}{l}\text { Million national } \\
\text { currency }\end{array}$ & 6223 & 607 & 48 & 54 \\
\hline \multicolumn{5}{|l|}{$\begin{array}{l}\text { (b2) National screening } \\
\text { system in } 2015 \text { (incl. } \\
\text { correction for health } \\
\text { care price level) }\end{array}$} \\
\hline Per screen (f) & 38 & 32 & 18 & 20 \\
\hline Million pound sterling & 65 & 84 & 44 & 15 \\
\hline $\begin{array}{l}\text { Million national } \\
\text { currency }\end{array}$ & 11849 & 972 & 44 & 54 \\
\hline
\end{tabular}


Table 1), the current female population aged $25-45$, which will constitute the population to be screened in 2015, is smaller in the U.K. than in France [18]. This explains the lower expecting screening costs in the U.K. in 2015 if compared with France (Table 3).

The cost-effectiveness ratios are calculated after applying a $5 \%$ discount rate to both the costs and the life-years gained, see Table 4. The screening costs are proportional to the population size, the additional costs for diagnosis and treatment are related to the incidence level and stage distribution. The savings on treatment of advanced disease are directly proportional to the mortality level and are relatively high in the U.K. and in the Netherlands. These two countries also show the most favourable

Table 4. The cost-effectiveness of mass screening by inviting women at age 50-70 2-yearly, for breast cancer in the four EC countries between 1990 and 2017. Costs and effects are discounted at 5\%, in 1990 prices

Spain France United Netherlands Kingdom

\begin{tabular}{|c|c|c|c|c|}
\hline \multicolumn{5}{|l|}{ (a) Effects } \\
\hline \multicolumn{5}{|l|}{ Life-years gained } \\
\hline Total & 79000 & 155000 & 252000 & 61000 \\
\hline Per 1000 screens & 3.9 & 5.2 & 9.0 & 7.5 \\
\hline \multicolumn{5}{|l|}{$\begin{array}{l}\text { (b1) Uniform screening } \\
\text { system }\end{array}$} \\
\hline \multicolumn{5}{|l|}{$\begin{array}{l}\text { Costs (in million pounds } \\
\text { sterling) }\end{array}$} \\
\hline Screening & 430 & 613 & 625 & 166 \\
\hline Assessment/treatment & 50 & 88 & 181 & 34 \\
\hline Advanced disease & -95 & -175 & -303 & 71 \\
\hline $\begin{array}{l}\text { Total (million pounds } \\
\text { sterling) }\end{array}$ & 385 & 526 & 503 & 129 \\
\hline Million national currency & 69800 & 6065 & 503 & 466 \\
\hline \multicolumn{5}{|l|}{$\begin{array}{l}\text { Cost-effectiveness ratios } \\
\text { (pounds sterling) } \\
\text { per life-year gained }\end{array}$} \\
\hline Pound sterling & 4900 & 3400 & 2000 & 2120 \\
\hline National currency & 880000 & 39500 & 2000 & 7650 \\
\hline $\begin{array}{l}\text { Relative to the } \\
\text { Netherlands }\end{array}$ & 2.3 & 1.6 & 0.9 & 1.0 \\
\hline $\begin{array}{l}\text { Relative to health care } \\
\text { expenditures per capita } \\
\text { (b2) National screening } \\
\text { system (corrected for } \\
\text { health care price level) }\end{array}$ & 10.4 & 3.8 & 3.4 & 2.8 \\
\hline \multicolumn{5}{|l|}{$\begin{array}{l}\text { Costs (in million pounds } \\
\text { sterling) }\end{array}$} \\
\hline Screening & 826 & 981 & 563 & 166 \\
\hline Assessment/treatment & 60 & 88 & 163 & 34 \\
\hline Advanced disease & -114 & -175 & -273 & -71 \\
\hline $\begin{array}{l}\text { Total (million pounds } \\
\text { sterling) }\end{array}$ & 772 & 894 & 453 & 129 \\
\hline Million national currency & 139920 & 10308 & 453 & 466 \\
\hline \multicolumn{5}{|c|}{$\begin{array}{l}\text { Cost-effectiveness ratios } \\
\text { (pounds sterling) } \\
\text { per life-year gained }\end{array}$} \\
\hline Pounds sterling & 9700 & 5800 & 1800 & 2120 \\
\hline National currency & 1770000 & 66900 & 1800 & 7650 \\
\hline $\begin{array}{l}\text { Relative to the } \\
\text { Netherlands }\end{array}$ & 4.6 & 2.7 & 0.9 & 1.0 \\
\hline $\begin{array}{l}\text { Relative to health care } \\
\text { expenditures per capita }\end{array}$ & 20.6 & 6.5 & 3.1 & 2.8 \\
\hline
\end{tabular}

cost-effectiveness ratio. The cost per life-year gained is 1.6 higher in France and nearly 2.3 higher in Spain if a specialised organisation is implemented in these countries.

The screening costs will increase by approximately $60 \%$ in France and Spain when an attached organisation is assumed. Adjustment of the screening costs for different health care price levels will further increase the costs in Spain, and slightly decrease screening costs in the U.K. (Table 3 ). This adjustment will also influence the additional costs for diagnosis and primary treatment, and the savings in treatment of advanced disease, see Table 4. As a result, the cost per life-year gained in France will be 2.7 higher and in Spain 4.6 higher than in the Netherlands.

The cost-effectiveness ratios can be put in perspective by making a comparison with the health care expenditures per capita in 1990. Our prediction for the cost per life-year gained in the Netherlands and the U.K. is approximately three times as high as the health care expenditures per inhabitant in these countries. When an attached organisation is considered, the cost per life-year gained in France is nearly seven times as high, and in Spain even more than 20 times as high as the health care expenditures per capita in those countries.

\section{DISCUSSION}

The cost-effectiveness ratios for breast cancer screening of approximately $£ 2000$ per life-year gained as predicted for the U.K. and the Netherlands are relatively favourable in comparison with many other health care facilities [9]. For example, cervical cancer screening, which is well-established in most European countries, has been shown to be at least three times as costly in terms of cost per life-year gained [24]. In the U.K., a special working group predicted that the policy proposed for the U.K. (3-yearly invitation between the ages of 50 and 65) would result in a cost-effectiveness ratio of just over $£ 3000$ per life-year gained [8]. Their estimate is higher for two main reasons: savings on treatment of advanced disease are neglected, and a smaller number of life-years gained is calculated, partly by neglecting effects occurring after the period when screening is carried out.

The estimates for the mortality reduction and cost per lifeyear gained are influenced by a number of uncertain factors and should not be interpreted as being very precise. The most important uncertainty is the reduction in risk of dying from breast cancer following early detection by screening [9]. These uncertainties will affect to the same extent the estimates for all countries under consideration.

Our exploratory calculations show that in comparison with the Netherlands the cost per life-year gained will be almost more than three times as high in France, and almost more than five times as high in Spain. However, the absolute value of the cost per life-year gained in these countries should be interpreted with some caution. Although we did take major differences into account, some of the differences between the countries have been neglected because of the lack of definite data. These factors should be taken into account if a more precise estimation of the costs and effects of breast cancer screening in these countries is required. The cost-effectivenesss outcomes are highly influenced by the incidence to mortality ratio in the countries. The additional impact of the stage distributions is only small, and more up-to-date or more exact estimates of these distributions will not affect our conclusions.

\section{Differences which have been neglected}

Other factors that may also be different between countries are: 
- The distinction between a specialised and an additive organisation of screening may not apply to a country as a whole. A nationwide specialised screening programme may probably not be realistic in France because of the already installed base of mammographic equipment in diagnostic centres which are linked to private practices and independent health examination centres. A similar situation exists in Spain. Nevertheless, a specialised breast cancer screening programme with an invitation system may be possible in some areas like in Strasbourg.

- With respect to the baseline situation regarding breast cancer, we assumed no difference in stage-specific survival of clinically diagnosed breast cancer between the four countries. Moreover, we assumed no trend in incidence or mortality, which is justified for the Netherlands in view of the small changes in the past decade. But increasing rates have been reported for other countries. Another possible trend might occur in the stage distribution of clinically diagnosed cancers [25]. Also, the cost of diagnosis and treatment of breast cancer may show further variations, for example, because of differences in treatment methods, length of stay in hospital, or in specialist and hospital costs.

- We assumed no differences in the stage-specific improvement in prognosis by screening nor in attendance rate. In practice, the breast cancer mortality reduction will depend on the coverage of the population, on the quality of the mammography, and on the adequacy of the diagnostic and therapeutic follow-up of screen-detected cancers. Participation rates differ widely within and between countries, and depend strongly on the use of an invitation system. In the Netherlands, attendance is at present well over $70 \%$, whereas French figures are between 30 and $50 \%$ [13].

However, differences in participation rates will have approximate equal proportionate effects on the costs and the mortality reduction, and we found that the impact on the cost-effectiveness ratio is only modest [9].

Quality control of mammographic screening is essential, and its effectuation might be more difficult in a nonspecialised organisation with small units. In a specialised programme, training programmes of radiographers, radiodiagnosts and pathologists, purchase of state-of-theart equipment, daily technical quality control of the equipment, double reading of mammograms, and monitoring of the screening results can be made an integral part of the organisation.

- False positive rates vary enormously between countries [26]. Further assessment is a heavy burden for the women involved. Combining mammograms for symptomatic cases and screening in a diagnostic unit in a non-specialised screening organisation could lead to high false positive rates, as has been found in the U.S.A. [27].

- We considered a single screening policy (ages 50-69, 2-yearly invitations), which is the policy that is being implemented in the Netherlands. Given the differences in cost-effectiveness for a uniform strategy, one could suggest to use a more modest policy in France and Spain. However, we found that a 3- or 4-yearly interval will only give a relative small improvement (15-18\%) in cost-effectiveness, which is due to the relatively short duration of the screendetectable stage of breast cancer in the age group considered $[9,11]$.

\section{Cost per life-year gained and consequences}

The comparison of the cost-effectiveness ratios between countries is not a straightforward one. We compared these ratios with the health care expenditures per capita in 1990 for each country. However, such an analysis has its limitations. A part of these health care expenditures consists of the costs of services which are only aimed at the improvement of quality of life. On the other hand, important non-medical costs of a good water system, sewerage, high quality food production, hygiene and so on, which influence the life expectancy of the inhabitants, are not included. The health care expenditures per capita are also influenced by the age structure of the population.

The cost-effectiveness ratio is expressed in life-years gained. For a direct comparison the average medical costs should not be expressed per inhabitant but in the number of life-years that are gained for the total population by the national health care system. Unfortunately, such information does not exist and is not to be expected in the foreseeable future.

Our calculations for France suggest a cost-effectiveness ratio which is almost three times as high as in the Netherlands. However, the health care expenditures per capita are also higher in France together with a higher GDP per capita, and a screening programme might, therefore, still be a realistic offering.

In Spain, health care expenditures per capita are much lower, and the GDP per capita is also lower, but health care is relatively more expensive than in the Netherlands. The high costs per lifeyear gained of breast cancer screening suggest that introduction of nationwide screening is not a very obvious proposition.

Breast cancer mortality figures for the EC countries show a marked north-south gradient: mortality in Ireland, Belgium, Luxembourg, and Denmark is high, at about the level of the U.K. and the Netherlands. Intermediate mortality levels (with important regional variation), comparable with France, are reported for Germany and Italy, and breast cancer mortality in Portugal and Greece is at about the same relatively low level as in Spain [10]. Our calculations for the four countries are, therefore, illustrative for the general variation in cost-effectiveness of breast cancer screening within the European Community.

\section{CONCLUSION}

The relatively favourable ratio between effects and costs of breast cancer screening has been one of the key elements in the decision to start nationwide screening programmes in the U.K. and in the Netherlands. Our results show that in France and especially in Spain the ratio between effects and costs is less favourable. The differences between the countries lead to the conclusion that one uniform policy recommendation for the whole European Community regarding breast cancer screening would be inappropriate.

1. Collette HJA, Rombach JJ, Day NE, de Waard F. Evaluation of screening for breast cancer in a non-randomized srudy (the DOM project) by means of a case-control study. Lancet 1984, 1, 1224-1226.

2. Verbeek ALM, Hendriks JHCL, Holland R, Mravunac M, Sturm ans F, Day NE. Reduction of breast cancer mortality through mass screening with modern mammography. First results of the Nijmegen project, 1975-1981. Lancet 1984, 1, 1222-1224. 
3. Tabár L, Gad A, Holmberg LH, et al. Reduction in mortality from breast cancer after mass screening with mammography. Randomized trials from the Breast Cancer Screening Working Group of the Swedish National Board of Health and Welfare. Lancet 1985, $i$, 829-832.

4. UK trial of Early Detection of Breast Cancer Group. First results on mortality reduction in the UK trial of Early Detection of Breast Cancer. Lancet 1988, ii, $41 \mathrm{l}-416$.

5. Andersson I, Aspergren K, Janzon L, et al. Mammographic screening and mortality from breast cancer: the Malmö mammographic screening trial. $\mathrm{Br} \mathrm{Med} \mathcal{F} 1988,297,943-948$.

6. Roberts MM, Alexander FE, Anderson TJ, et al. Edinburgh trial of screening for breast cancer: mortality at seven years. Lancet 1990 , 335, 241-246.

7. Rutqvist LE, Miller AB, Andersson I, et al. Reduced breast cancer mortality with mammography screening - an assessment of currently available data. Int $\mathcal{f}$ Cancer 1990, suppl. 5, 76-84.

8. Forrest P. Breast Cancer Screening. Report to the Health Ministers of England, Wales, Scotland and Northern Ireland. London 1986.

9. Koning $H J$ de, Ineveld $B M$ van, Oortmarssen GJ van, et al. Breast cancer screening and cost-effectiveness; policy alternatives, quality of life considerations and the possible impact of uncertain factors. Int 7 Cancer 1991, 49, 531-537.

10. Møller Jensen O, Estéve J, Møller H, Renard H. Cancer in the European Community and its member states. Eur $\mathcal{f}$ Cancer 1990, 26, 1167-1256

11. Maas PJ van der, Koning HJ de, Ineveld BM, et al. The costeffectiveness of breast cancer screening. Int $\mathcal{F}$ Cancer 1989, 43, $1055-1060$.

12. Lancry JP, Fagnani F. Evaluation Economique du Dépistage Systematique des Cancers du Sein et du Col de l'Uterus. COMAC-HSR, Paris, 1989.

13. Brown ML, Kessler LG, Rueten FG. Is the supply of mammography machines outstripping need and demand? Ann Intern Med 1990 $113,547-552$.

14. Habbema JDF, Lubbe JThN, Oortmarssen GJ van, Maas PJ van der. A simulation approach to cost-effectiveness and cost-benefit calculations of screening for early detection of disease. Eur $\mathcal{F}$ Oper Res 1987, 29, 159-166.

15. Oortmarssen GJ van, Habbema JDF, Maas PJ van der, et al. A model for breast cancer screening. Cancer 1990, 66, 1601-1612.

16. WHO (World Health Organization). Cancer Incidence in Five Continents. Volume V. IARC Scientific Publication, Lyon, 1987.

17. WHO (World Health Organization). World Health Statistics, Geneva, 1989.

18. UN (United Nations). Demographic Yearbook 1987. New York, 1987.

19. CBS (Central Bureau of Statistics). Monthly Bulletin of Health Statistics. Volume 4, Voorburg, 1985.

20. Koning $\mathrm{HJ}$ de, Oortmarssen GJ van, Ineveld $B M$ van, Maas $P J$ van der. Breast cancer screening: its impact on clinical medicine. $\mathrm{Br} \mathcal{F}$ Cancer 1990, 61, 292-297.

21. Koning HJ de, Ineveld BM van, Haes JCJM de, Oortmarssen GJ van, Klijn JGM, Maas PJ van der. Advanced breast cancer and its prevention by screening. Br $\mathcal{F}$ Cancer 1992, 65, 950-955.

22. OECD (Organization for Economic Co-operation and Development). Purchasing Power Parities and Real Expenditures 1985. Paris, 1987.
23. OECD (Organization for Economic Co-operation and Development). Health Data File. Paris, 1991.

24. Ballegooijen $M$ van, Habbema JDF, Oortmarssen GJ van, Koopmanschap MA, Lubbe JThN, Agt HME van. Preventive Papsmears: striking the balance between costs, risks and benefits. $\operatorname{Br} \mathcal{F}$ Cancer 1992, 65, 930-933.

25. Bennett IC, McCaffrey JF, Baker CA, Burke MF, Lee JF, Balderson $\mathrm{GA}$. Changing patterns in the presentation of breast cancer over 25 years. Austr N Z F Surg 1990, 60, 665-671.

26. United Kingdom Trial of Early Detection of Breast Cancer Group. Specificity of screening in United Kingdom Trial of Early Detection of Breast Cancer. Br Med $\mathcal{F} 1992,304,346-349$.

27. Kopans DB, Swann CA. Observations on mammographic screening and false-positive mammograms. Am $\mathcal{F}$ Röntgenol 1988, 150, 785-786.

Acknowledgements-We thank Prof. Frans F.H. Rutten, Ph.D., for his comments on previous versions of this article. Further thanks to Mrs A.E. de Bruyn.

\section{APPENDIX}

Stage distribution of breast cancer in the four countries

Table Al presents the breast cancer stage distribution in clinical and in screen detected patients. The clinical stage distribution, which is a parameter of the MISCAN breast cancer model, has been specified as shown in order to reproduce the incidence-mortality ratio in the countries. The distributions in screen-detected cancers are predicted by the model for the screening policy with 2-yearly invitations in age-group 50-70 years, and $70 \%$ attendance on average. The distribution on the Netherlands are based on analyses of data from the pilot projects in Nijmegen and Utrecht $[1,2]$.

Table A1. Stage distribution (\%) for breast cancer detected without screening and for screen-detected cancers for the four EC countries

Spain France United The
Kingdom Netherlands

\begin{tabular}{lrrrr}
$\begin{array}{l}\text { Clinical detection (without } \\
\text { screening) }\end{array}$ & & & & \\
DCIS & 4.7 & 4.8 & 4.8 & 4.9 \\
$<10 \mathrm{~mm}$ & 7.9 & 14.9 & 4.1 & 7.5 \\
$10-19 \mathrm{~mm}$ & 23.8 & 31.7 & 10.7 & 22.7 \\
$\geqslant 20 \mathrm{~mm}$ & 63.6 & 48.6 & 80.5 & 64.9 \\
$\begin{array}{l}\text { Detection at screening } \\
\text { DCIS }\end{array}$ & 13.3 & 14.7 & 10.4 & 13.3 \\
$<10 \mathrm{~mm}$ & 23.5 & 25.2 & 18.1 & 22.6 \\
$10-19 \mathrm{~mm}$ & 41.9 & 41.6 & 35.8 & 42.4 \\
$\geqslant 20 \mathrm{~mm}$ & 21.3 & 18.5 & 35.7 & 21.7 \\
\hline
\end{tabular}

DCIS = ductal carcinoma in situ 